\title{
Fraud Risk Assessment and Detection of Fraud: The Moderating Effect of Personality
}

\author{
Nahariah Jaffar (Corresponding author) \\ Faculty of Management, Multimedia University \\ Jalan Multimedia, 63100 Cyberjaya, Selangor, Malaysia \\ Tel: 60-3-8312-5678Ｅ-mail: nahariah.jaffar@mmu.edu.my \\ Hasnah Haron \\ School of Management, Universiti Sains Malaysia \\ 11800 Penang, Malaysia \\ E-mail: hhasnah@usm.my \\ Takiah Mohd Iskandar \\ School of Accounting, Faculty of Economics and Business Management \\ Universiti Kebangsaan Malaysia \\ 43600 Bandar Baru Bangi, Selangor, Malaysia \\ E-mail: takiah@pkrisc.cc.ukm.my \\ Arfah Salleh \\ Graduate School of Management, Universiti Putra Malaysia \\ 43400 UPM Serdang, Selangor, Malaysia \\ E-mail: arfah@putra.upm.edu.my
}

Received: January 21, 2011 Accepted: February 11, 2011 doi:10.5539/ijbm.v6n7p40

\begin{abstract}
External auditors are required by the auditing standards to provide reasonable assurance that the financial statements are free from material misstatements. Inability of the external auditors to detect material misstatements, particularly fraud, may expose the external auditors to litigation. The present study aims to examine the moderating effect of personality factors (that are neuroticism, extraversion, conscientiousness, openness to experience and agreeableness) on the relationship between the external auditors' ability to assess fraud risk and their ability to detect the likelihood of fraud. The present study utilizes an experimental approach by sending case materials to audit partners or audit managers attached to auditing firms operating in Malaysia. The result, however, shows that none of the personality factors has moderating effect on the relationship between the external auditors' ability to assess fraud risk and their ability to detect the likelihood of fraud.
\end{abstract}

Keywords: Fraud, Fraud risk assessment, Personality factor, Fraud detection, External auditors' ability

\section{Introduction}

The issue of fraud is very important for public accountants because litigation actions may be taken against them should they not able to detect fraud during the conduct of the audit (Feroz, Park \& Pastena, 1991 and Palmrose, 1987). Palmrose (1987) describes that business failures and management fraud cause legal actions to be brought against auditors and the settlement of such actions. For instance, when Xerox was sanctioned for overstating earnings by US\$3 billion, its auditor KPMG was liable for US\$22 million in penalties (Ettredge, Sun, Lee \& Anandarajan, 2005). In Malaysia, fraudulent activities were also found to be occurred in its public companies for example the former case of Bumiputra Malaysia Finance (BMF) and the recent case of Transmile Bhd.

Although fraud may not be well documented in Malaysia, this issue could not be taken lightly because what happened in other countries, for instance in the United States is the case of Enron, could happen elsewhere. Furthermore, the issue is made more important based on the findings by KPMG Malaysia's (2003) ${ }^{1}$ survey that external auditors only detected $4 \%$ of the fraud incidences. 
The present study is an extension of the study done by Jaffar, Salleh, Iskandar and Haron (2008) that examined the effect of the external auditors' ability to assess fraud risk on their ability to detect the likelihood of fraud. Jaffar et al. (2008) found that in a high fraud risk scenario, the external auditors' ability to assess fraud risk has a positive effect on their ability to detect the likelihood of fraud, whereas in a low fraud risk scenario not. The present study extends Jaffar et al. (2008) by adding a factor, that is personality, as another variable that may affect the ability to detect the likelihood of fraud. This attempt is essential since Jaffar et al. (2008) discovered that in a different fraud risk situation the findings demonstrate different results concerning the effect of the ability to assess fraud risk on the ability to detect the likelihood of fraud. The present study predicts that there might be other factor that affect the external auditor's job performance, that is in the context of the present study is his/her ability to detect the likelihood of fraud.

Many studies on job performance (for example Barrick \& Mount, 1993; Gellatly, 1996) had shown that personality influenced job performance. In addition, Ashton (1999) suggests that certain innate personality factors can be used as predictors of performance in accounting. In fraud detection literature very limited studies (Pincus, 1984; Bernardi, 1994, Zimbelman \& Waller, 1999 and Jaffar, Hasnah, Iskandar and Salleh, 2010) had examined the effect of personality factor on the ability to detect the likelihood of fraud. Those studies, however, show inconclusive results. The present study predicts that personality might have only moderating effect on the fraud detection ability. Within this context, the present study examines Big-5 factors of personality (that are neuroticism, extraversion, conscientiousness, openness to experience and agreeableness) because these factors are the basic dimensions of personality and it is predominantly viewed that many personality traits are subsumed under these five factors (McCrae \& John, 1992). Literature shows mixed results concerning the effect of the Big-five personality factors on job performance. Thus the present study takes the first attempt to investigate the moderating effects of the personality factors on the relationship between the external auditors' ability to assess fraud risk and their ability to detect the likelihood of fraud.

\section{Literature Review and Hypotheses Development}

\subsection{Detection of Fraud}

Literature on the ability to detect the likelihood of fraud shows that factors that have investigated in this issue can be categorized into several dimensions namely audit task, personality, cognitive factors, auditor's ethical status, auditor's characteristics, audit firm's characteristics, audit firm's roles, auditor's roles and fraud risk indicators. AI 240 on Fraud and Error (MIA, 1997) ${ }^{2}$ requires the auditor to assess the risk of fraud during the conduct of the audit. Analysis of the literature discovers that there is only one study, which is by Jaffar et al. (2008) that tested the effect of ability to assess fraud risk on the ability to detect the likelihood of fraud. The present study aims to extend Jaffar et al. (2008) by investigating the possible effect of other factor on the relationship between the external auditors' ability to assess fraud risk and their ability to detect the likelihood of fraud.

Literature shows that very limited studies (Pincus, 1984; Bernardi, 1994; Zimbelman \& Waller, 1999 and Jaffar et al., 2010) had investigated the effect of the external auditor's personality on his/her ability to detect the likelihood of fraud. However, only Pincus (1984) found direct effect of personality on ability to detect the fraud. The present study aims to investigate this construct from different perspective, because literature (for example Evans, Kiggundu \& House, 1979) has shown that personality may moderate the relationship between a construct and job performance. The present study examines the Big-5 factors of personality (that are neuroticism, extraversion, conscientiousness, openness to experience and agreeableness) because these factors are the basic dimensions of personality and it is predominantly viewed that many personality traits are subsumed under these five factors (McCrae \& John, 1992). In the literature, only Jaffar et al (2010) had investigated the effect of Big-5 factors of personality on fraud detection ability. The study, however, demonstrate that no significant effect between external auditors' personality and their ability to detect the likelihood of fraud. Thus, the present study predicts that personality could be only have a moderating effect on th external auditors' job performance. The present study, therefore, is undertaken to investigate the moderating effects of five basic personality factors (that are neuroticism, extraversion, conscientiousness, openness to experience and agreeableness) on the external auditor's job performance, particularly the detection of fraud.

The present study will contribute to the literature through providing evidences on the fraud detection ability of the external auditors in Malaysia. Notwithstanding the importance of the other eight dimensions which were investigated before, personality is the focus of the present study because it is a fundamental aspect of the external auditor and might influence their job performance. Thus, the present study suggests that personality factors may to some extent have moderating effect on the external auditor's ability to detect the likelihood of fraud.

\subsection{Attribution Theory}

Similar to Jaffar et al. (2008), Attribution theory is adopted by the present study to explain the effect of the external auditor's ability to assess fraud risk on the ability to detect the likelihood of fraud. This theory suggests that the level of future expected performance, in a particular task depends mainly on the particular causes to which prior success or failure in the same task is attributed. This theory is appropriate to the present study, 
because of the need to assess the causal attribution of the external auditors' performance, i.e. ability to detect the likelihood of fraud. Applying this theory to the present study, the level of the future expected ability to detect the likelihood of fraud is attributed by the external auditors' prior ability to assess the level of fraud risk.

According to the Attribution theory, the effect of previous success or failure in detecting the likelihood of fraud on subsequent expectations varies according to whether the attribution is internal (that is ability to assess fraud risk) or external (for example difficulty of the fraud risk assessment task). In the present study, however, focus is given on the internal attribution. Hence, prior success (or failure) of the ability of the external auditors to assess fraud risk is viewed as having a greater chance of being repeated, that is through the subsequent ability to detect the likelihood of fraud. In other words, if the external auditors are able to appropriately assess fraud risk (AI 240, MIA, 1997) based on their professional judgments (AI 240, AI 400, MIA, 1997), this attribution will subsequently influence their ability to detect the likelihood of fraud.

With the assumption that other factors will remain constant, the present study predicts that the external auditors' ability to assess fraud risk will influence their ability to detect the likelihood of fraud in a positive direction. In order to test whether the requirements of AI 240 (MIA, 1997), AI 400 (MIA, 1997), the literature and the insight of the Attribution Theory are held, the present study hypothesizes that the external auditors' ability to assess fraud risk has a positive effect on their ability to detect the likelihood of fraud. With that, the first hypothesis to be tested is:

H1: Ability to assess fraud risk is positively related to ability to detect the likelihood of fraud.

\subsection{Five-factor theory}

The view of this model is that the five-factor of personality exists in which many traits names are subsumed under five constructs:

- Surgency or extraversion (e.g. active, assertive, energetic, outgoing)

- Agreeableness (e.g. appreciative, generous, trusting)

- Conscientiousness (e.g. efficient, organized, reliable)

- Emotional stability or neuroticism (e.g. anxious, self-pitying, worrying)

- Intellectance or openness (e.g. curious, artistic)

Source: McCrae, R.R. and John, O.P.(1992).An Introduction to the 5-factor Model and Its Application.Jornal of Personality, 60(2), 175-215.

\subsubsection{Neuroticism as a personality trait}

Mixed results are found regarding the effect of neuroticism on job performance (e.g. Eysenck \& Eysenck, 1985; Barrick, Mount \& Judge, 2001; Barrick \& Mount, 1993; Kraus, 2002). The prediction of the present study is that external auditors who are high on neuroticism will not be able to perform effectively in their job, as compared to those who are low on neuroticism, because those with high neuroticism tend to show negative attitudes. The present study predicts that if such attitudes are demonstrated, the external auditors may not be able to appropriately detect the likelihood of fraud. Hence, the present study proposes that in any fraud risk situation, high on neuroticism would diminish the relationship between the ability to assess fraud risk and the ability to detect the likelihood of fraud, if one exists. Thus the second hypothesis of the present study is:

H2: $\quad$ High neuroticism will have a negative effect on the relationship between the ability to assess fraud risk and the ability to detect the likelihood of fraud.

\subsubsection{Extraversion as a personality trait}

Mixed results are also found regarding the effects of extraversion on job performance (Barrick \& Mount, 1991; Barrick \& Mount, 1993; Stewart \& Carson, 1995; Barrick, Mount \& Strauss, 1993; Kraus, 2002; Organ \& Ryan, 1995; Mount, Barrick \& Stewart, 1998). The prediction of the present study is that when a person is experiencing positive emotions, it may influence them to perform well in their job. The present study proposes, in any risk situation, high on extraversion would have positive influence on the relationship between the external auditors' ability to assess fraud risk and their ability to detect the likelihood of fraud, if one exists. Therefore, the next hypothesis is:

H3: High extraversion will have a positive effect on the relationship between the ability to assess fraud risk and the ability to detect the likelihood of fraud.

\subsubsection{Conscientiousness as a personality trait}

Literature presents mixed results concerning the effect of concientiousness on job performance (e.g. Barrick \& Mount, 1991; Gellatly, 1996; Barrick \& Mount, 1993; Kraus, 2002; Lehmann, 2001; Stewart \& Carson, 1995; Mount, Barrick \& Stewart, 1998). The prediction of the present study is that an individual who has a high level of conscientiousness should perform well in the job because characters such as organized, reliable, detail conscious and planful are important facets for carrying out auditing tasks. Hence, the present study proposes that, in any risk situation, high on conscientiousness would have positive influence on the relationship between the 
external auditors' ability to assess fraud risk and their ability to detect the likelihood of fraud, if one exists. Thus, the next hypothesis to be tested is:

H4: High conscientiousness will have a positive effect on the relationship between the ability to assess fraud risk and the ability to detect the likelihood of fraud.

\subsubsection{Openness to experience as a personality trait}

Mixed results are also found concerning the effects of openness to experience on job performance (Barrick et al., 2001; Barrick \& Mount, 1991; Bing \& Lounsbury, 2000; Marsh, Kiechel Koles, Boyce \& Zacaro, 2001 and George \& Zhou, 2001; Kraus, 2002). The prediction of the present study is that if an external auditor is more open to experience, he/she should be more able to detect the likelihood of fraud, if one exists. The present study predicts that possessing traits such as intellectually curious, behaviourally flexible, and nondogmatic in attitude and values may be considered as essential in the conduct of an auditing task. Therefore, the present study proposes that in any risk situation, high on openness to experience will have a positive influence on the relationship between the external auditors' ability to assess fraud risk and their ability to detect the likelihood of fraud, if one exists. Hence, the next hypothesis is:

H5: High openness to experience will have a positive effect on the relationship between the ability to assess fraud risk and the ability to detect the likelihood of fraud.

\subsubsection{Agreeableness as a personality trait}

Literature offers mixed results concerning the effect of agreeableness on job performance (e.g. Barrick \& Mount, 1991; Barrick \& Mount, 1993; Kraus, 2002; Mount, Barrick \& Stewart, 1998). The prediction of the present study is that an external auditor who demonstrates high level of agreeableness in his/her personality should be more able to detect the likelihood of fraud, if one exists because it is presumed that personality such as cooperativeness, trustfulness and adaptability would make them more competent in performing their jobs. The present study proposes that, in any risk situation, high on agreeableness trait will positively influence the relationship between the external auditors' ability to assess fraud risk and their ability to detect the likelihood of fraud. With that, the next hypothesis is:

H6: High agreeableness will have a positive effect on the relationship between the ability to assess fraud risk and the ability to detect the likelihood of fraud.

\section{Research Method}

\subsection{Research design}

The present study adopts a $2 \times 2$ within subject factorial experimental design representing two levels of ability to assess fraud risk and two levels of each dimension of personality factor. The two treatment levels of ability to assess fraud risk are correct fraud risk assessed and incorrect fraud risk assessed. The dimensions of personality factors are neuroticism, extraversion, conscientiousness, openness to experience, and agreeableness. Each dimension is manipulated along high and low level of personality.

\subsection{Research instrument}

\subsubsection{Case material}

The present study developes the case materials by modifying those of Zimbelman (1996), Brief, Dukerich, Brown and Brett (1996), and Moet (1997). Two versions of case study (high fraud risk case and low fraud risk case) are developed for a hypothetical company, XYZ Manufacturing Bhd.. The subjects are required to assume that they are involved in the audit of this company.

\subsubsection{Psychological test}

A psychological test is conducted to measure the subjects' Big-five factors of personality using Goldberg 50 Big-five Factors Markers instrument.

\subsection{Sample}

Practicing independent auditor registered in Malaysia, designated as audit partner or audit manager who are attached to the auditing firms operating in Malaysia is the sample group of the present study. Database regarding the numbers of audit partners and audit manager in Malaysia, however,is not availabe. Database of auditing firms operating in Malaysia was obtained from the MIA website and as at May 2006 there are 1370 firms registered with MIA. The present study distributes the research materials to all these auditing firms. Due to the actual total population of audit partners and audit managers attached to the auditing firms operating in Malaysia is unknown, the present study used all auditing firms operating in Malaysia as perceived population.

\subsection{Administration of the research instrument}

The research instruments were mailed directly to the auditing firms. The cover letter stated clearly that the subjects must attempt both sets of the research materials. The time to be taken to attempt the research materials was also stated in the letter, which is approximately 45-50 minutes. A stamped self-address envelope is provided for the convenience of the subjects to return the questionnaire. 


\subsection{Variables of the study}

\subsubsection{Dependent variable}

The dependent variable is the external auditors' ability to detect the likelihood of fraud. It is measured on a 7-point Likert scaling ranging from extremely unlikely to extremely likely, by asking the subject: "Based on your judgment, what is the likelihood that the management of XYZ Manufacturing Bhd. would fraudulently misrepresent the financial statements?. An answer "likely" and above indicates that the fraud is considered to have been detected.

\subsubsection{Independent variable}

The independent variable is the external auditors' ability to assess fraud risk. It is operationalised through the inclusion of a question in Part A requiring the subject to indicate on a 7-point Likert scale ranging from extremely low to extremely high, his/her assessment of the risk of material misstatement in the financial statements due to fraud.

\subsubsection{Moderating variable}

The moderating variable is Big-five factors of personality and is measured using the personality test. The subjects are required to describe their behaviours on a 7-point Likert scale ranging from extremely inaccurate (1) to extremely accurate (7).

\subsubsection{Control variables}

The procedure adopted by the present study to control contaminating variable is by sending the research materials to all auditing firms as the perceived population of audit partners and audit managers. The present study controls the auditor's experience (which falls under the auditor's characteristics dimension) and fraud risk (which falls under fraud risk factors dimension).

\subsubsection{Auditor's experience}

Auditor's experience was found to have a significant effect on the ability to detect fraud (e.g. Pincus, 1984; Bernardi, 1994 etc.). The present study uses position levels, audit partner or audit manager, as a proxy for experience (Knapp, 1995; Knapp \& Knapp, 2001 etc.). These positions are used because both individuals are as the person in-charge of the audit work and the individuals are expected to have extensive experience in audit. Thus, the present study controls the auditor's experience by selecting the audit partner and audit manager as the subjects.

\subsubsection{Fraud risk factors}

Mixed results were found regarding the effect of fraud risk indicators on the ability to detect the likelihood of fraud (Bernardi, 1994; Matsumura \& Tucker, 1997 etc.). Given that AI 240 (MIA, 1997) requires the auditor to assess the risk of fraud and provides some examples of the conditions that may increase the risk of fraud, it is expected that these cues alone may lead the auditor to suspect the possibility of fraud. With the fraud being embedded in the case material it is essential that the fraud risk indicators be controlled in this study.

\section{Results and Discussion}

\subsection{Reliability analysis}

An analysis of the reliability of the measurement scale is carried out on the personality test and a cronbach alpha coefficient is 0.771 which is greater than 0.6 indicating acceptable internal consistency of measure of scale reliability used in the present study (Sekaran 2000).

\subsection{Hypotheses testing}

\subsubsection{Test for the relationship between ability to assess fraud risk and ability to detect the likelihood of fraud}

Hypothesis 1 is developed to examine whether the external auditors' ability to assess fraud risk impact their ability to detect the likelihood of fraud. The expectation of the present study is, if the subjects are able to assess fraud risk correctly, they should be able to detect the likelihood of fraud. Since the personality factors are tested individually, hypothesis 1 shall be discussed under each of the tests conducted on the individual personality factor by examining the main effects of the external auditors' ability to assess fraud risk on their ability to detect the likelihood of fraud.

Tables 1 demonstrate the results of general linear model repeated measures ANOVA. The multivariate tests indicate insignificant ability to assess fraud risk main effects with $p=0.598,1.000,0.544,0.897$ and 0.460 for each test (i.e. based on the individual personality factor) respectively. This means that the means on the ability to detect the likelihood of fraud are not different between high ability to assess fraud risk and low ability to assess fraud risk. This is shown in the Wilks $\lambda$ values, $0.958,1.000,0.945,0.997$ and 0.857 for the respective personality traits, which are close to 1 indicating that the group means are not different.

Table 1 show that partial eta squared values are $0.042,0.000,0.055,0.003$ and 0.143 , for each test, which are close to 0 . These results indicate that the strengths of association between the ability to assess fraud risk and ability to detect the likelihood of fraud, are relatively weak. Meanwhile, the observed powers are relatively very 
low for each test, $0.077,0.050,0.086,0.052$ and 0.098 , indicating that the probability of identifying a treatment effect; i.e. the effect of the ability to assess fraud risk on the ability to detect the likelihood of fraud, when it actually exists is very low. These findings do not support Hypothesis 1 that the ability to assess fraud risk is positively related to the ability to detect the likelihood of fraud.

4.2.2 Test for the effect of neuroticism on the relationship between the ability to assess fraud risk and the ability to detect the likelihood of fraud

Hypothesis 2 is developed to examine whether neuroticism as a personality factor has a moderating effect on the relationship between the external auditors' ability to assess fraud risk and their ability to detect the likelihood of fraud. The expectation of the present study is, high neuroticism will have a negative effect on the relationship between the ability to assess fraud risk and the ability to detect the likelihood of fraud.

The results in Table 1 demonstrate a non-significant ability to assess fraud risk-by-neuroticism interaction effect, Wilks $\lambda=1.000, \mathrm{~F}(1,7)=0.000, p=1.000$. These findings indicate that the interaction effect does not exist between the ability to assess fraud risk, neuroticism and ability to detect the likelihood of fraud. The Wilks $\lambda$ is 1 indicating the group means are not different. The partial eta-squared is 0.000 indicating that the strength of association between ability to assess fraud risk, neuroticism and ability to detect the likelihood of fraud is relatively very weak. In addition, the observed power is relatively very low, 0.050 , indicating that the probability of identifying a treatment effect i.e. the effect of neuroticism on the relationship between the ability to assess fraud risk and the ability to detect the likelihood of fraud, when it actually exists is very low. Hence, it can be concluded that neuroticism does not have a moderating effect on the relationship between the ability to assess fraud risk and the ability to detect the likelihood of fraud. These findings do not support Hypothesis 2 that high neuroticism will have a negative effect on the relationship between the ability to assess fraud risk and the ability to detect the likelihood of fraud.

4.2.3 Test for the effect of extraversion on the relationship between the ability to assess fraud risk and the ability to detect the likelihood of fraud

Hypothesis 3 is developed to examine whether extraversion as a personality factor has a moderating effect on the relationship between the external auditors' ability to assess fraud risk and the ability to detect the likelihood of fraud. The expectation is, high extraversion will have a positive effect on the relationship between the ability to assess fraud risk and the ability to detect the likelihood of fraud.

The results in Table 1 demonstrate a non-significant ability to assess fraud risk-by-extraversion interaction effect, Wilks $\lambda=0.952, \mathrm{~F}(1,4)=0.204, p=0.675$. This finding indicates that the interaction effect does not exist between the ability to assess fraud risk, extraversion and ability to detect the likelihood of fraud. The Wilks $\lambda$ is close to 1 indicating the group means are not different. The partial eta-squared is 0.048 indicating that the strength of association between the ability to assess fraud risk, extraversion and ability to detect the likelihood of fraud is very weak. In addition, the observed power is very low, 0.065 , indicating that the probability of identifying a treatment effect; i.e. the effect of extraversion on the relationship between the ability to assess fraud risk and the ability to detect the likelihood of fraud, when it actually exists is very low. Hence, it can be concluded that extraversion does not have a moderating effect on the relationship between the ability to assess fraud risk and the ability to detect the likelihood of fraud. These findings do not support Hypothesis 3 that high extraversion will have a positive effect on the relationship between the ability to assess fraud risk and the ability to detect the likelihood of fraud.

4.2.4 Test for the effect of conscientiousness on the relationship between the ability to assess fraud risk and the ability to detect the likelihood of fraud

Hypothesis 4 is developed to examine whether conscientiousness as a personality factor has a moderating effect on the relationship between the external auditors' ability to assess fraud risk and their ability to detect the likelihood of fraud. The expectation of the present study is, high conscientiousness will have a positive effect on the relationship between the ability to assess fraud risk and the ability to detect the likelihood of fraud.

The results in Table 1 demonstrate a non-significant ability to assess fraud risk-by-conscientiousness interaction effect, Wilks $\lambda=0.995, \mathrm{~F}(1,7)=0.035, p=0.857$. These findings indicate that the interaction effect does not exist between the ability to assess fraud risk, conscientiousness and ability to detect the likelihood of fraud. The Wilks $\lambda$ is close to 1 indicating the group means are not different. The partial eta-squared is 0.005 indicating that the strength of association between the ability to assess fraud risk, conscientiousness and ability to detect the likelihood of fraud is very weak. In addition, the observed power is very low, 0.053 , indicating that the probability of identifying a treatment effect; i.e. the effect of conscientiousness on the relationship between the ability to assess fraud risk and the ability to detect the likelihood of fraud, when it actually exists is very low. Hence, it can be concluded that conscientiousnsess does not have a moderating effect on the relationship between the ability to assess fraud risk and the ability to detect the likelihood of fraud. These findings do not support Hypothesis 4 that high conscientiousness will have a positive effect on the relationship between the ability to assess fraud risk and the ability to detect the likelihood of fraud. 
4.2.5 Test for the effect of openness to experience on the relationship between the ability to assess fraud risk and the ability to detect the likelihood of fraud

Hypothesis 5 is developed to examine whether openness to experience as a personality factor has a moderating effect on the relationship between the external auditors' ability to assess fraud risk and the ability to detect the likelihood of fraud. The expectation is, high openness to experience will have a positive effect on the relationship between the ability to assess fraud risk and the ability to detect the likelihood of fraud.

The results in Table 1 demonstrate a non-significant ability to assess fraud risk-by-openness to experience interaction effect, Wilks $\lambda=0.966, \mathrm{~F}(1,7)=0.247, p=0.634$. These findings indicate that the interaction effect does not exist between the ability to assess fraud risk, openness to experience and ability to detect the likelihood of fraud. The Wilks $\lambda$ is close to 1 indicating the group means are not different. The partial eta-squared is 0.034 indicating that the strength of association between the ability to assess fraud risk, openness to experience and ability to detect the likelihood of fraud is very weak. In addition, the observed power is very low, 0.072 , indicating that the probability of identifying a treatment effect; i.e. the effect of openness to experience on the relationship between the ability to assess fraud risk and the ability to detect the likelihood of fraud, when it actually exists is very low. Hence, it can be concluded that openness to experience does not have a moderating effect on the relationship between the ability to assess fraud risk and the ability to detect the likelihood of fraud. These findings do not support Hypothesis 5 that high openness to experience will have a positive effect on the relationship between the ability to assess fraud risk and the ability to detect the likelihood of fraud.

4.2.6 Test for the effect of agreeableness on the relationship between the ability to assess fraud risk and the ability to detect the likelihood of fraud

Hypothesis 6 is developed to examine whether agreeableness as a personality factor has a moderating effect on the relationship between the external auditors' ability to assess fraud risk and their ability to detect the likelihood of fraud. The expectation of the present study is, high agreeableness will have a positive effect on the relationship between the ability to assess fraud risk and the ability to detect the likelihood of fraud.

The results in Table 1 demonstrate a non-significant ability to assess fraud risk-by-agreeableness interaction effect, Wilks $\lambda=0.496, \mathrm{~F}(1,4)=4.072, p=0.144$. These findings indicate that the interaction effect does not exist between the ability to assess fraud risk, agreeableness and ability to detect the likelihood of fraud. The Wilks $\lambda$ is close to 1 indicating the group means are not different. The partial eta -squared is 0.504 indicating that the strength of association between the ability to assess fraud risk, agreeableness and ability to detect the likelihood of fraud is moderately weak. In addition, the observed power is low, 0.341 , indicating that the probability of identifying a treatment effect; i.e. the effect of agreeableness on the relationship between the ability to assess fraud risk and the ability to detect the likelihood of fraud, when it actually exists is low. Hence, it can be concluded that agreeableness does not have a moderating effect on the relationship between the ability to assess fraud risk and the ability to detect the likelihood of fraud. These findings do not support Hypothesis 6 that high agreeableness will have a positive effect on the relationship between the ability to assess fraud risk and the ability to detect the likelihood of fraud.

\subsection{Discussion}

\subsubsection{Hypothesis 1 is not supported}

The results show that the external auditors' ability to assess fraud risk does not have a positive effect on the external auditors' ability to detect the likelihood of fraud. This finding is not corroborated with the assumption of the Attribution Theory that the level of the future expected ability to detect the likelihood of fraud is attributed by the external auditor's prior ability to assess fraud risk. The findings do not support the insight of the Attribution Theory where although the external auditors apparently have used fraud risk indicators when deciding on fraud risk assessment, their success of assessing fraud risk is not attributed to their ability to detect the likelihood of fraud. Thus, the present study advocates that when the external auditors suspect fraud has occurred in the financial statements based on the fraud risk indicators, the assessed fraud risk does not serve as a guide to them to identify the high risk area, for instance an account that is possibly materially misstated. Besides that the inability of the external auditor to detect the likelihood of fraud may be due to external cause such as task difficulty (Weiner, Frieze, Kukla, Reed, Rest \& Rosenbaum, 1971). In other words, fraud risk assessment task is difficult to perform, thus lead to the inability of the external auditor to detect the likelihood of fraud.

The findings of the present study indicate that the external auditors' ability to detect the likelihood of fraud, when given several fraud risk indicators, do not depend on the external auditors' ability to assess fraud risk after considering those indicators. This is similar with the results of Jaffar et al. (2008) for low fraud risk scenario. In other words, the ability to detect the likelihood of fraud is not attributed by the ability to assess fraud risk.

The finding does not support the expectations of the standards that if the external auditors are able to appropriately assess fraud risk (AI 240, MIA, 1997) based on their professional judgments (AI 240, AI 400, MIA, 1997), this attribution will subsequently influence the ability of the external auditor to detect the likelihood of fraud (AI 240, MIA 1997). 


\subsubsection{Hypothesis 2 is not supported}

High on neuroticism does not have a negative effect on the relationship between the ability to assess fraud risk and the ability to detect the likelihood of fraud. The result for H2 does not support the literature (Steers \& Spencer, 1977) on the moderating role of personality factor on the relationship between a construct and job performance. However, the finding corroborates Evans et al. (1979) who find that personality factor does not moderate the relationship between autonomy and performance ratings.

The present study, thus, concludes that external auditors who are high on neuroticism, i.e. in which they may have problematic organizational habits and work attitudes, may not necessary not performing well in their job. The results do not support Eysenck and Eysenck (1985) who demonstrate that neuroticim is negatively associated with performance. Moreover, high neuroticism which reflects negative attitudes such as unstable, anxious, worrying and lack of courage, may not negatively impact the external auditors' job performance in terms of the detection of the likelihood of fraud. This may be because the subjects, as professionals, although having such attitudes may be able to control their emotions and attitudes especially in a tense situation related with the nature of auditing work.

\subsubsection{Hypotheses 3 is not supported}

High on extraversion does not have a positive effect on the relationship between the ability to assess fraud risk and the ability to detect the likelihood of fraud. The results for $\mathrm{H} 3$ does not support the literature (Steers \& Spencer, 1977) on the moderating role of personality factor on the relationship between a construct and job performance. However, the finding corroborates Evans et al. (1979) who find that the personality factor does not moderate the relationship between autonomy and performance ratings.

The present study, therefore, concludes that external auditors who experience positive emotions may not necessarily perform well in their job. These findings consistent to those of Barrick et al. (1993), Stewart and Carson (1995) and Kraus (2002) who demonstrate that extraversion is not related to job performance. Particularly, Stewart and Carson (1995) find an inverse relation between extraversion and performance in service jobs. According to Rose, Murphy, Byard and Nikzad (2002) since extraverts are lower in arousability (i.e. sensitivity), it would be predicted that their performance would be equal or superior to introverts on demanding and tedious task. Thus, perhaps the present study can concludes that being low in sensitivity leading the external auditors less sensitive to the indicators of fraud and less sensitive to the audit evidence, thus make them not able to detect the likelihood of fraud. Moreover, high on extraversion which reflects traits such as sociable, needing people, friends and cohorts and craving excitement does not necessarily impact the external auditors' job performance in terms of detecting the likelihood of fraud. This may be due to the nature of the auditing work that does not necessary require such attitudes. In addition, majority of the subjects have professional qualifications (e.g. MICPA, CIMA etc.) which may reflect that they have a professional attitude during the conduct of the audit. In addition, as reported by Barrick et al. (1993) extraversion may not be important to certain job due to the nature of the job. Therefore, the present study concludes that based on the nature of the auditing work which requires auditor to perform professional judgment, extraversion may be less important.

\subsubsection{Hypotheses 4 is not supported}

High on conscientiousness does not have a positive effect on the relationship between the ability to assess fraud risk and the ability to detect the likelihood of fraud. The results for $\mathrm{H} 4$ does not support the literature (Steers \& Spencer, 1977) on the moderating role of personality factor on the relationship between a construct and job performance. However, the finding corroborates Evans et al. (1979) who find that the personality factor does not moderate the relationship between autonomy and performance ratings.

The present study, therefore, concludes that traits such as being achievement-oriented, organized, careful, and detail-oriented may not necessarily influence the external auditors to perform well in their job. In other words these traits does not necessarily have an impact on the external auditors' job performance in terms of the detection of the likelihood of fraud.

\subsubsection{Hypotheses 5 is not supported}

High on openness to experience does not have a positive effect on the relationship between the ability to assess fraud risk and the ability to detect the likelihood of fraud. The results for H5 does not support the literature (Steers \& Spencer, 1977) on the moderating role of personality factor on the relationship between a construct and job performance. However, the finding corroborates Evans et al. (1979) who find that the personality factor does not moderate the relationship between autonomy and performance ratings.

The present study, therefore, concludes that external auditors who are intellectually curious, independent thinkers and amendable to experiences may not necessarily perform well in their job. Barrick et al. (2001) state that openness to experience yielded consistently low correlations with job performance. Meanwhile, Barrick and Mount (1991) and Kraus (2002) find a negative relationship between openness to experience job performance. In addition, Griffin and Hesketh (2004) reveal that openness to external experience is negatively related to job tension. Within this context perhaps that having traits such as adventurousness, intellect and liberalism are not 
important to external auditors since they are expected to perform professionalism and are governed by the professional by-laws. Thus, they are aware of the importance to act accordingly to the professional requirement. Moreover, high on openness to experience which reflects traits such as preference of variety above routine, open-minded and motivated by a need for understanding does not impact the external auditors' job performance in terms of the detection of the likelihood of fraud.

\subsubsection{Hypotheses 6 is not supported}

High on agreeableness does not have a positive effect on the relationship between the ability to assess fraud risk and the ability to detect the likelihood of fraud. The results for H6 does not support the literature (Steers \& Spencer, 1977) on the moderating role of personality factor on the relationship between a construct and job performance. However, the finding corroborates Evans et al. (1979) who find that the personality factor does not moderate the relationship between autonomy and performance ratings.

The present study, therefore, concludes that external auditors who possess traits such as altruism, nurture, caring, and emotional support may not necessary perform well in their job. Barrick and Mount (1993) reveal a negative correlation between agreeableness and job performance in jobs with high autonomy. Kraus (2002) finds that the relationship between agreeableness and overall job performance did not reach statistical significance. High on agreeableness which reflects traits such as trusting, sympathetic and cooperative may not impact the external auditors' job performance in terms of the detection of the likelihood of fraud. This may be due to the nature of the auditing work that may not requires such attitudes. In addition, attitudes such as trusting and cooperativeness may not be important to external auditors. This is because being external auditors, the present study presumes that the individuals show an attitude of professionalism. This is supported by the fact that majority of the subjects possess professional qualifications. Besides, Barrick and Mount (1993) find that managers who are softhearted, courteous, forgiving, trusting and cooperative perform better in jobs that do not provide much discretion in the way the work behaviour are performed. Perhaps in the present study also such attitudes are not important because the nature of the audit work requires some amount of discretion.

\section{Conclusion}

Literature has shown that fraudulent financial reporting has occurred in many countries (e.g. Mitchell, 1997; Grant, 1999 and Spathis, 2002). Nevertheless, after the establishment of the Sarbanes-Oxley Act in 2002, fraud incidence still occurs. Similarly, in Malaysia, despite standards and guidelines were issued, yet the fraudulent financial reporting still occurred in this country as reported by the KPMG Malaysia (2003). Although guidance has already been provided by the Malaysian standards, KPMG Malaysia (2005) reported that the external auditors discovered only 3\% of fraud incidences in Malaysian companies. Hence, the public may question why external auditors are not able to detect fraud during the conduct of the annual audit. Thus the present study advocates that it is important to know the factors affecting the ability of the external auditors to detect fraud. Future research in this area may be done by investigating whether risk attitude has an effect on the external auditor ability to detect the likelihood of fraud.

\section{References}

Ashton, R.H. (1999). Enriching the "Expertise Paradigm" ofaccounting research: Conscientiousness, general cognitive ability and goal orientation. In Lehmann, C.M. (2001). The effects of experience, instruction and personality factors on complex problem representation and performance in auditing:an experimental investigation. Doctoral Dissertation, Texas A\&M University.

Barrick, R.M., and Mount, K.M. (1993). Autonomy as a moderator of the relationships bBetween the big five personality dimensions and job performance. Journal of Applied Psychology, 78(1), 111-118.

Barrick, R.M., Mount, K.M., and Strauss, P.J. (1993). Conscientiousness and performance of sales representatives: Test of the mediating effects of goal setting. Journal of Applied Psychology, 78(5), 715-722.

Barrick, R.M., Mount, M.K., and Judge, T.A. (2001). Personality and performance at the beginning of the new millennium: What do we know and where do we go next?. In Griffin, B. and Hesketh, B. (2004). Why openness to experience is not a good predictor of job performance. International Journal of Selection and Assessment, 12(3), 243-251.

Bernardi, R.A. (1994). Fraud detection: The effect of client integrity and competence and auditor cognitive style. Auditing: A Journal of Practice \& Theory, 13, 68-84.

Bing, M.N., and Lounsbury, J.W. (2000). Openness and job performance in U.S.-based Japanese manufacturing companies. In Griffin, B. and Hesketh, B. (2004). Why openness to experience is not a good predictor of job performance. International Journal of Selection and Assessment, 12(3), 243-251.

Brief, A.P., Dukerich, J.M., Brown, P.R., and Brett, J.F. (1996). What's wrong with the Treadway Commission Report?. Journal of Business Ethics, 15(2), 183-198.

Ettredge, M., Sun, L., Lee, P., \& Anandarajan, A. (2005). Using deferred tax data to detect fraud. [Online] Available: $\mathrm{http}: / /$ ssrn.com/abstract $=826587$. 
Evans, M.G., Kiggundu, M.N., and House, R.J. (1979). A partial test and extension of the job characteristics model of motivation. Organisational Behaviour \& Human Performance, 24(3), 354-381.

Eysenck, H.J., and Eysenck, S.B.G. (1975). Manual of the Eysenck personality questionnaire. In Janowsky, A. (2004). Actor-observer differences in the Big-Five Personality Factors: An information-processing explanation. Doctoral Dissertation, Florida Atlantic University.

Feroz, E.H., Park, K., \& Pastena, V.S. (1991). The financial and market effects of the SEC's accounting and auditing enforcement releases. Journal of Accounting Research, 29, (Supplement), 107-142.

Gellatly, R.I. (1996). Conscientiousness and task performance: Test of cognitive process model. Journal of Applied Psychology, 81(5), 474-482.

George, J., and Zhou, J. (2001). When openness to experience and conscientiousness are related to creative behaviour: An interactional approach. In Griffin, B. and Hesketh, B. (2004). Why openness to experience is not a good predictor of job performance. International Journal of Selection and Assessment, 12(3), 243-251.

Grant, J. (1999). Detecting Management Fraud. Balance Sheet, 7(3), 14-15.

Griffin, B., \& Hesketh, B. (2004). Why openness to experience is not a good predictor of Job Performance. International Journal of Selection and Assessment, 12, (3), 243-251.

Jaffar, N., Hasnah, H. Iskandar, T.M., and Salleh, A. (2010). Effect of personality on fraud detection: The Malaysian case. Journal of Modern Accounting and Auditing, 6, 8, 47-54.

Jaffar, N., Salleh, A., Iskandar, T.M., and Hasnah, H. (2008). The effects of the external auditors' ability to assess fraud risk on their ability to detect the likelihood of fraud. International Journal of Management Perspectives, 1(1), 49-70.

Knapp, C.A. (1995). The use of fraud schema during analytical procedures: Effects of experience, client explanations and attentional cues. Doctoral Dissertation, The University of Oklahoma.

Knapp, C.A., and Knapp, M.C. (2001). The effects of experience and explicit fraud risk assessment in detecting fraud with analytical procedures. Accounting, Organisations and Society, 26, 1, 25-37.

KPMG Malaysia. (2003). Fraud Survey 2002 Report.

KPMG Malaysia. (2005). Fraud Survey 2004 Report.

Kraus, E. (2002). Personality and job performance: The mediating roles of leader-member exchange quality and action control. Doctoral Dissertation, Florida International University.

Lehmann, C.M. (2001). The effects of experience, instruction and personality factors on complex problem representation and performance in auditing: An experimental investigation. Doctoral Dissertation, Texas A\&M University.

Malaysian Institute of Accountants (MIA). (1997). Malaysian Approved Standards on Auditing.

Marsh, S.M., Kieche Koles, K.L., Boyce, L.A., and Zaccaro, S.J. (2001). Leader emergence and functional leadership: The role of leader traits and information provision in adaptive situations. In Griffin, B. and Hesketh, B. (2004). Why openness to experience is not a good predictor of job performance. International Journal of Selection and Assessment, 12, 3, 243-251.

Matsumura, E.M., and Tucker, R.R. (1992). Fraud detection: A theoretical foundation. The Accounting Review, 67, 4, 753-782.

McCrae, R.R., and John, P.O. (1992). An introduction to the Five-Factor Model and its applications. Journal of Personality, 60, 2, 175-215.

Mitchell, H.S. (1997). Management fraud trends. The Secured Lender, 53, 6, 104-108.

Moet, L.K. (1997). Will SAS No. 88 aid auditors in financial statement fraud detection. Doctoral Dissertation, University of Colorado.

Mount, M.K., Barrick, M.R., and Stewart, G.L. (1998). Five-factor model of personality and performance in jobs involving interpersonal interactions. Human Performance, 11, 2/3, 145-165.

Palmrose, Z. (1987). Litigation and independent auditors: The role of business failures and management fraud. Auditing: A Journal of Practice \& Theory, 6, 2, 90-103.

Pincus, V.K. (1984). Fraud detection ability: Individual differences and their relationship to cognitive style Difference. Doctoral Dissertation, The University of Maryland.

Rose, L.C., Murphy, B.L., Byard, L., \& Nikzad, K. (2002). The role of the big five personality factors in vigilance performance and workload. European Journal of Personality, 16, 3, 185-200.

Sarbanes-Oxley Act of 2002; United States of America, 2002.

Sekaran, U. (2000). Research methods for business. United States of America: John Wiley \& Sons.

Spathis, T.C. (2002). Detecting false financial statements using published data: Some evidence from Greece. 
Managerial Auditing Journal, 17, 4, 179-191.

Steers, E.F., and Spencer, D.G. (1977). The role of achievement motivation in job design. Journal of Applied Psychology, 62, 4, 472-479.

Stewart, G.L., and Carson, K.P. (1995). Personality dimensions and domains of service performance: A field investigation. Journal of Bunsiness \& Psychology, 9, 4, 365-378.

Weiner, B., Frieze, I., Kukla, A., Reed, L., Rest, S., \& Rosenbaum, R.M. (1971). Perceiving the cause of success and failure. In Orpen, C. (1980). The relationship between expected job performance and causal attributions of past success or failure. The Journal of Social Psychology, 112, 151-152.

Zimbelman, M.F. (1996). Assessing The risk of fraud in audit planning. Doctoral Dissertation, The University of Arizona.

Zimbelman. F.M., and Waller, S.W. (1999). An experimental investigation of auditor-auditee interaction Under Ambiguity. Journal of Accounting Research, 7 (supplement),135-155.

\section{Notes}

Note 1. 2004 KPMG Fraud Survey revealed that the external auditor detected only $3 \%$ of fraud incidences in Malaysia (KPMG, 2005).

Note 2. AI 240 is now known as The Auditor's Responsibility to Consider Fraud in an Audit of Financial Statements.

Table 1. Results for GLM repeated measures ANOVA

\begin{tabular}{|c|c|c|c|c|c|c|c|c|}
\hline & Effect & $\begin{array}{c}\text { Wilks' } \lambda \\
\text { Value }\end{array}$ & $\mathbf{F}$ & $\begin{array}{c}\text { Hypothesis } \\
\text { df }\end{array}$ & Error df & Sig. & $\begin{array}{l}\text { Partial Eta } \\
\text { Squared }\end{array}$ & $\begin{array}{l}\text { Observed } \\
\text { Power(a) }\end{array}$ \\
\hline \multirow{2}{*}{$\begin{array}{l}\text { Ability to assess } \\
\text { fraud risk, } \\
\text { neuroticism and } \\
\text { ability to detect } \\
\text { the likelihood of } \\
\text { fraud }\end{array}$} & $\begin{array}{l}\text { Ability to } \\
\text { assess fraud } \\
\text { risk }\end{array}$ & 0.958 & 0.304 & 1.000 & 7.000 & 0.598 & 0.042 & 0.077 \\
\hline & $\begin{array}{l}\text { Ability to } \\
\text { assess fraud } \\
\text { risk * } \\
\text { neuroticism }\end{array}$ & 1.000 & 0.000 & 1.000 & 7.000 & 1.000 & 0.000 & 0.050 \\
\hline \multirow{2}{*}{$\begin{array}{l}\text { Ability to assess } \\
\text { fraud risk, } \\
\text { extraversion and } \\
\text { ability to detect } \\
\text { the likelihood of } \\
\text { fraud }\end{array}$} & $\begin{array}{l}\text { Ability to } \\
\text { assess fraud } \\
\text { risk }\end{array}$ & 1.000 & 0.000 & 1.000 & 4.000 & 1.000 & 0.000 & 0.050 \\
\hline & $\begin{array}{l}\text { Ability to } \\
\text { assess fraud } \\
\text { risk * } \\
\text { extraversion }\end{array}$ & 0.952 & 0.204 & 1.000 & 4.000 & 0.675 & 0.048 & 0.065 \\
\hline \multirow{2}{*}{$\begin{array}{l}\text { Ability to assess } \\
\text { fraud risk, } \\
\text { conscientiousness } \\
\text { and ability to } \\
\text { detect the } \\
\text { likelihood of } \\
\text { fraud }\end{array}$} & $\begin{array}{l}\text { Ability to } \\
\text { assess fraud } \\
\text { risk }\end{array}$ & 0.945 & 0.406 & 1.000 & 7.000 & 0.544 & 0.055 & 0.086 \\
\hline & $\begin{array}{l}\text { Ability to } \\
\text { assess fraud } \\
\text { risk * } \\
\text { conscientious- } \\
\text { ness }\end{array}$ & 0.995 & 0.035 & 1.000 & 7.000 & 0.857 & 0.005 & 0.053 \\
\hline \multirow{2}{*}{$\begin{array}{l}\text { Ability to assess } \\
\text { fraud risk, } \\
\text { openness to } \\
\text { experience and } \\
\text { ability to detect } \\
\text { the likelihood of } \\
\text { fraud }\end{array}$} & $\begin{array}{l}\text { Ability to } \\
\text { assess fraud } \\
\text { risk }\end{array}$ & 0.997 & 0.018 & 1.000 & 7.000 & 0.897 & 0.003 & 0.052 \\
\hline & $\begin{array}{l}\text { Ability to } \\
\text { assess fraud } \\
\text { risk * } \\
\text { openness to } \\
\text { experience }\end{array}$ & 0.966 & 0.247 & 1.000 & 7.000 & 0.634 & 0.034 & 0.072 \\
\hline \multirow{2}{*}{$\begin{array}{l}\text { Ability to assess } \\
\text { fraud risk, } \\
\text { agreeableness and } \\
\text { ability to detect } \\
\text { the likelihood of } \\
\text { fraud }\end{array}$} & $\begin{array}{l}\text { Ability to } \\
\text { assess fraud } \\
\text { risk }\end{array}$ & 0.857 & 0.667 & 1.000 & 4.000 & 0.460 & 0.143 & 0.098 \\
\hline & $\begin{array}{l}\text { Ability to } \\
\text { assess fraud } \\
\text { risk } * \\
\text { agreeableness }\end{array}$ & 0.496 & 4.072 & 1.000 & 4.000 & 0.144 & 0.504 & 0.341 \\
\hline
\end{tabular}

(a) Computed using alpha $=0.05 \quad * 5 \%$ significance level 